\title{
Joan Solà (26 octubre 2010)
}

\author{
JÚLIA BUTINYÀ \\ (UNED)
}

Amb data d'avui, ja revisant les proves del volum 15 , ens sorprèn la notícia de la mort del gran lingüista i bon amic Joan Solà.

No ens arriba però el temps per a fer una ressenya acurada de la seva obra, però tampoc no volem endarrerir la nostra adhesió als records que hom li farà dins del mateix any. Especialment havent comptat amb la seva col-laboració des dels primers temps d'aquesta publicació, així com amb la seva presència als orígens de les nostres activitats universitàires a les Universitats de Madrid.

Així, el vam convidar a participar als començaments de les Jornades comparatatistes, que l'any 1991 celebràrem conjuntament la UNED amb la Universitat Autònoma de Madrid i la d'Alcalà d'Henares. El professor Solà intervingué el 24 d'abril, a la Complutense d'Alcalà, amb una visió gobal sobre la Situació lingüística, social i política del català, que aparegué en aquesta publicació, en 1992, aleshores titulada Jornadas de Lengua y Literatura Catalana, Gallega y Vasca, donat que es reduia pràcticament a recollir aquelles Actes. Finalment el vam tenir amb nosaltres arran de la cancessió dels Doctorats Honoris Causa a quatre permalitats de les llengüas d'Espanya, recollit en el present número de la nostra revista.

Potser el millor homenatge que en podem fer és de donar-ne una descripció, tornant a donar vida a aquelles paraules seves.

Començà referint-se al títol que haviem donat en principi a la seva intervenció: vida i mort del català, ja que el 1990 havia sortit el llibre de Modest Prats, August Rafanell i Albert Rossich, El futur de la llengua catalana, estudi i auguri tan escandalós com comercial que presagiava el mal final, el qual ja es trobava aleshores a la $3^{\mathrm{a}}$ edició. El benvolgut professor Solà ens va a especificar que acceptà el títol arran de la nostra conversa telefònica d'invitació, a l'igual que Bernardo Atxaga, que ho enfocava des de la llengua basca, títol però que va variar el professor Alonso Montero, menys submís i necrofílic, com ens diu al començament del treball. La seva intervenció va donar una perspectiva de conjunt ben valuosa per aquelles dades, ja que entre els mesos d'octubre a març, ell mateix havia comptat 9 llibres polèmics al voltant de la salut del català, a càrrec 
de Pazos, Vallverdú, Prats-Rafanell-Rossich, Sabater. Reixach, Royo, Joan, Burguera i Actes.

Joan Solà es concentrà en l'anàlisi — viu i realista sobretot— de la llengua catalana des dels tres angles que marcava al títol definitiu: Situación lingüística, social y política del catalán. Al primer punt es fixà en l'orientació de la llengua cap a un model lingüístic, arrencant dels Jocs Florals - que justament constituïen un altre tema comparatista d'aquelles Jornades- del 1859; i, després, en el punt tan delicat de la llengua del carrer, la col-loquial. S'hi feia palès la mala salut de la llengua a causa de la invasió, sobretot lèxica de barbarismes. Ho demostrà amb exemples fefaents del gran desastre ecològic. (Cal ressaltar que, com era característic de la seva parla, emprava un llenguatge irònic tot al llarg de la seva conferència).

En la situació social donà unes dades diferenciant el coneixement passiu $\mathrm{i}$ l'actiu del català; el panorama feia conscients de les reculades lingüístiques, bé del seu coneixement bé de l'ús com a llengua de relació. Quant a l'aspecte polític, el feia dependre de les reglamentacions o dels textos legals corresponents; i tot i no definir-se com a sociolingüista, recollia l'opinió de Lluís Aracil, compartida també per altres, com ara Bastardas - desaparegut així mateix fa pocs anys-, qui la concretava al reclam d'una llei lingüística d'àmbit estatal, tot considerant que és un mal endèmic que ha de ser solucionat amb una intervenció dràstica.

Clou el treball amb una sèrie de propostes per aquest canvi radical per tal d'evitar que s'arribi a una situació irreversible. Reproduïm fragments dels dos darrers paràgrafs a tall de conclusió: de tot ben valent, com queda constatat al llarg del treball i com ho ha estat sempre el bon amic perdut; i alhora divertit, com mostra l'ombra d'altra figura llavors molt de moda i popular, la de Superman.

«Para terminar, recordemos el principio básico de la supervivencia de las lenguas. Las lenguas son como los demás valores del intercambio humano: sólo interesan, sólo pueden resistir si son útiles y necesarias. He aquí el gran reto: conseguir que sean útiles y necesarias por lo menos en su propio territorio... Les ruego que se armen ustedes de valor, porque la fórmula no es fácil de digerir: nuestras lenguas minoritarias sólo serán útiles en su territorio en la medida en que deje de serlo el castellano. Este reto sólo se puede plantear, claro está, si de verdad, no sólo en el articulado, este país quiere salvar estas lenguas y proyectarlas llenas de vigor hacia el futro de Europa.

A cualquiera que oiga estas palabras no se le escapará que una lengua no es algo que vaya solo por el mundo. Nuestras lenguas, para sobrevivir, necesitan condiciones políticas y sociales excepcionales, sí; pero también tendrán que luchar contra unas condiciones económicas y tecnológicas hoy dificilísimas... Las preguntas con que inevitablemente hay que terminar son éstas: ¿Querrán nuestras comunidades hacer frente a una problemática tan grave, urgente y compleja? ¿Podrán?» 